\title{
A LOGÍSTICA DENTRO DA CONSTRUÇÃO ENXUTA: ESTUDO DE CASO EM UMA CONSTRUTORA DE FORTALEZA ${ }^{1}$
}

\section{RESUMO}

Dentro da abordagem da gestão de cadeia de suprimentos, este artigo abordará por meio de um estudo de caso sobre uma construtora de Fortaleza, como filosofias como o Just in time podem estar relacionadas com a eficiência logística em empresas de diversos setores. Por meio da descrição de práticas relacionadas à implantação de ferramentas de racionalização de estoque e otimização de processos construtivos fica evidente como as empresas têm obtido resultados da migração do pensamento tradicional para um novo olhar sobre as atividades produtivas, inclusive a logística.

Palavras-chave: Construção civil. Logística. Just-in-time.

\section{INTRODUÇÃO}

Atualmente, as empresas têm apresentado de várias formas sua preocupação com a intensa concorrência, característica do mercado contemporâneo. Assim, diminuir custos por meio da otimização de atividades produtivas é um grande desafio para empresas de vários setores. As atividades em que se transformam matérias primas por meio da utilização de mão de obra e de outros insumos em bens e serviços foram aos poucos sendo repensadas a fim de trazer melhores retornos.

$\mathrm{Na}$ medida em que os processos produtivos evoluem, com intensa influência de filosofias de trabalho que se tornaram bastante conhecidas em todo o mundo, houve também a preocupação de se repensar a gestão de outras atividades ligadas à produção, como

Andriele Pinto de Amorim andriele.pintodeamorim7@ gmail.com Bacharel em Administração pelo Centro Universitário Christus Fortaleza-CE-BR

Larisse Oliveira Costa larisseocosta@hotmail.com Doutora em Logística - IPAG/ CRET-LOG - Paris - FR a logística. No entanto, para que houvesse a efetivação de filosofias como o Just in time, coube a setores como a construção civil, migrar de um pensamento tradicional para uma nova mentalidade.

A construção civil fora há muito tempo reconhecida por seu baixo nível de planejamento e improviso que redundava em resultados negativos como o desperdício, por exemplo. Após a percepção das vantagens da inserção da filosofia da produção limpa e depois de intensos estudos sobre a aplicabilidade de ferramentas lean no setor construtivo, uma "nova filosofia" surge: a construção 
enxuta. Esta prática que tem por objetivo a redução de desperdícios na construção por meio da implantação de ferramentas como kanbans, entre outros, tem trazido diversos benefícios.

Indaga-se por meio deste estudo, qual a influência da filosofia do Just In Time na atividade de produção da construção civil?

Tendo em vista a importância da redução de desperdícios e a otimização de processos produtivos da construção civil, este trabalho pretende demonstrar por meio de um estudo de caso em uma construtora situada na cidade de Fortaleza à importância do Just in time para a logística. De forma especifica, pretende-se reconhecer as várias práticas ligadas à produção enxuta na empresa.

\section{GESTÃO DA PRODUÇÃO E LOGÍS- TICA}

A administração das empresas é subdividida em diversas funções e nela se encontra a gestão ou administração da produção. Conceitua-se Administração da Produção como o "campo do conhecimento que cuida do planejamento, da organização e do controle da produção industrial e da prestação de serviço." Pode-se entender a produção, como um sistema em que os elementos físicos e de informação interagem entre si com o objetivo de gerar um bem ou serviço (MOREIRA, 2012, p.16).

Por estarem presentes em um ambiente competitivo, as operações produtivas são impactadas e diversos outros processos vão se tornando estratégicos para a eficiência em produção das organizações. Tratando-se da gestão da produção, a logística é uma área extremamente importante para a correta efetivação de seu sistema. Assim, fala-se em racionalização das atividades logísticas a qual propõe como as empresas podem aperfeiçoar seus recursos de suprimento, estoques e distribuição de produtos ao planejarem, organizarem e controlarem suas atividades, objetivando proporcionar níveis adequados de serviços a seus clientes campo em que a logística envolve desde a chegada da matéria prima até a disposição final para o uso ou consumo de bens (POZO, 2010).
Tendo em consideração diversas características da dinâmica mercadológica, que colocam as empresas em situação de declínio econômico e que as levam a se voltar para o Governo, chama-se a atenção para o fato de que, se as empresas buscassem tornar-se mais eficientes na manutenção da qualidade de suas operações, seria possível que "as políticas adotadas para a sobrevivência a levassem ao crescimento". (DIAS, 2010, p. 1). Para o autor, um dos fatores relevantes nesse processo de melhoria são a inclusão e a dinamização do sistema logístico. Assim, diversos setores como a construção civil devem avançar na busca por uma melhor eficiência produtiva pelo aperfeiçoamento de seus processos logísticos.

A indústria da construção civil foi por muito tempo associada ao desperdício e à falta de inovação devido a um longo período de pouca concorrência, o que resultou em pouca importância dada à logística. No entanto, no cenário atual de intensa concorrência no setor, a logística vem recebendo maior atenção e se tornando uma atividade essencial para a sobrevivência das empresas desse setor (BARBOSA; MUNIZ; SANTOS, 2008).

Para esses autores, a aplicação da logística na construção civil pode ser feita de maneira semelhante ao uso pelas indústrias manufatureiras, em que o canteiro de obras pode ser identificado como uma unidade produtiva por abranger em toda a cadeia de suprimentos diversas atividades que vão desde o manuseio à armazenagem.

Dada a realidade mercadológica, a logística está associada ao esforço por parte dos gestores, na procura de "uma vantagem competitiva sustentável e defensável". Dessa forma, a gestão da cadeia de suprimentos propõe a união das diversas energias presentes em toda a cadeia produtiva, pretendendo entre outras coisas, a redução de custos, por meio da agregação de valor aos produtos finais, pela:

a) redução de volume de transações de informações;

b) limitação de custos de transporte e estocagem e; 
c) diminuição da variabilidade da demanda de produtos e serviços finais (POZO, 2010).

\subsection{EVOLUÇÃO DOS PROCESSOS PRODUTIVOS: JUST IN TIME}

Existem diversos tipos de produção que apresentam múltiplas características, entre elas, o volume e a variação dos tipos de produtos. Dessa forma, são sistemas de produção: sistema de produção por projeto; de produção intermitente e de produção contínua. Todos esses processos são conhecidos como sistemas clássicos de produção, característicos do século XX. Com o passar do tempo, entretanto, a gestão da produção passou a apresentar tanto contribuições quanto desperdício, os quais eram vistos como uma consequência natural da ação produtiva; foi quando uma nova filosofia surgiu com o propósito de racionalizar os processos produtivos: o Just in Time. (MOREIRA, 2012).

No decorrer da evolução do pensamento produtivo, esse conceito influenciou as empresas na busca por um melhor desempenho em suas operações logísticas e a redução de desperdícios em diversos setores como é o caso da construção civil. Esta filosofia de produção baseia-se na eliminação de todo desperdício e na melhoria contínua da produtividade (ARNOLD, 1999).

As indústrias de veículos foram pioneiras como usuárias do Just in time em suas linhas de montagem depois do seu surgimento no Japão, na década de 1970 e após sua expansão para o ocidente, uma década depois, quando a meta do "zero estoque" propiciou a agregação de três elementos primordiais para a produção japonesa: redução de tempo, alta qualidade e preços competitivos (DIAS, 2010).

Um dos princípios fundamentais da produção enxuta é a ideia de agregar valor. Segundo Arnold (1999, p. 451), "muitas atividades aumentam custos sem adicionar valor e, tanto quanto possível, essas atividades devem ser eliminadas". Tais atividades que não agregam valor podem estar presentes em diversas etapas, seja no processo, na movimentação, e no estoque, por exemplo.
A fim de se atingir as metas do sistema JIT, diversas ferramentas foram criadas a fim de pôr a ideia em prática. O kanban é reconhecido como uma das técnicas mais utilizadas, podendo ser definido como um instrumento que interpreta de forma prática as filosofias desse sistema. Por meio do kanban, ou cartão, pode-se identificar, entender e ajustar os processos produtivos, sem interromper o fluxo de trabalho. Associado ao planejamento de produção, programa-mestre, o kanban, dentro do sistema JIT, pode promover intensas melhorias e minimização de desperdícios (DIAS, 2010).

Com a evolução do pensamento da produção enxuta e sua ampla aplicação, percebeu-se, ao longo do tempo que esta poderia também ser aplicada à construção civil, apesar das diversas diferenças entre o canteiro de obras e uma linha de produção. Lauri Koskela, pesquisador finlândes foi o responsável pela formulação de uma teoria que aplicasse os conceitos do Lean production à construção, seria o lean construction (KOSKELA, 1992 apud MOURÃO; VALENTE, 2013).

A eliminação de desperdício é possível graças a três componentes básicos; segundo Pozo, (2010) devem ser estabelecidos:

a) balanceamento sincronizado e fluxo no processo de produção;

b) ação em relação à qualidade priorizando a ideia de "fazer certo da primeira vez," e

c) o envolvimento de todos os funcionários.

A atividade construtiva envolve diversas particularidades que podem enquadrar-se em diversos princípios que são peculiares à construção enxuta. Primeiramente, ela reconhece que algumas atividades não agregam valor ao processo, devendo estas ser reduzidas; em seguida, reconhece-se que se agrega valor ao produto ao considerar as necessidades dos clientes; também as variabilidades dos processos devem ser reduzidas, bem como o tempo do ciclo de produção global; enfatiza-se, também, que as partes do processo podem ser reduzidas objetivando a uma racionalização do processo, au- 
mentando a flexibilidade e a saída do produto e ainda a transparência dos processos; deve haver um foco no controle global do processo, introduzindo uma melhoria contínua do processo. Tudo isso deve ter como motivação a busca pelo equilíbrio entre a melhoria das atividades de fluxo de conversão e considera-se que a empresa deva prezar pela realização de benchmarking (ISSATO et al., 2000 apud MOURÃO; VALENTE, 2013).

\section{METODOLOGIA}

O estudo foi realizado em uma empresa do setor da construção civil, sediada em Fortaleza/CE, que atua há mais de três décadas na construção de edifícios residenciais para as classes A e B, apresentando como filosofia de gestão a "evolução contínua" de seus processos por meio da continuidade e do aprimoramento da qualidade de suas edificações e inovação, absorvendo as práticas mais modernas da construção civil como a produção enxuta e a construção sustentável.

Quanto à classificação, esta pesquisa é qualitativa. A pesquisa qualitativa é usada quando não se torna possível quantificar as informações obtidas. Por essa razão, a análise dos dados será feita de forma indutiva. (MATIAS-PEREIRA, 2012). Esta pesquisa é classificada como qualitativa pelo fato de se buscar uma visão ampla e a compreensão do tema em questão de forma subjetiva.

Existem diferentes tipos de pesquisa, sendo estas classificadas segundo alguns critérios. Vergara (2013, p. 61) classifica as pesquisas quanto aos fins e quanto aos meios:

$\mathrm{Na}$ classificação quanto aos fins pode ser: a) exploratória; b) descritiva; c) explicativa) metodológica; e) aplicada; f) metodológica. Quanto aos meios: a) pesquisa de campo; b) pesquisa de laboratório) documental; d) bibliográfica; e) experimental; f) ex post facto; g) participante; h) pesquisa ação; i) estudo de caso.

Esta pesquisa, segundo a classificação acima é descritiva quanto aos fins e bibliográfica quanto aos meios, e estudo de caso. Como pesquisa descritiva, tem por objetivo descrever as informações sobre a organização. Segundo Collis e Hussey (2005) a pesquisa descritiva está relacionada a um fenômeno em que ela busca descrever como este fenômeno se comporta e tem em seu contexto um problema ou uma questão usada para a identificação e a obtenção de informações sobre ele.

Em segundo lugar, a pesquisa é bibliográfica, pois se utilizou de materiais publicados anteriormente em catálogos e endereços eletrônicos disponíveis na empresa. Rodrigues (2007, p. 44) assim conceitua: "pesquisa bibliográfica é a pesquisa limitada à busca de informações em livros e em outros meios de publicação".

Esta pesquisa ainda se classifica como um estudo de caso, pois discorre sobre as características de uma empresa de forma descritiva. Segundo Cooper e Schindler (2011, p. 186) o estudo de caso "é uma metodologia de pesquisa poderosa que combina entrevistas individuais e (às vezes) em grupo com a análise de registros e observação". O processo relacionado à coleta de dados foi realizado por meio de consulta a material bibliográfico publicado e cedido pela empresa que apresenta diversas práticas da construtora e experiências com o uso da filosofia lean, bem como aborda vários exemplos de práticas de construção sustentável.

\section{ESTUDO DE CASO}

O entendimento da filosofia de produção enxuta como modelo de gestão para a construtora estudada iniciou-se ainda em 2004 quando a empresa teve a oportunidade de participar de um treinamento promovido pelo INOVACON, Programa de Inovação da Indústria da Construção Civil do Estado do Ceará. Percebeu-se que os princípios da construção enxuta por meio da proposta de agregar valor aos clientes e pela busca da melhoria contínua eram compatíveis com a mentalidade da cultura da construtora que é a evolução contínua. Então, a partir do aprofundamento dessa filosofia, o processo 
de implementação do Lean Construction nos canteiros de obras iniciou-se (MOURÃO; VALENTE, 2013).

A filosofia da produção enxuta conferiu à empresa a necessidade de adaptação. Como exemplo de aprimoramento de seu planejamento, pode ser citada a adoção, a partir de então, da metodologia hierarquizada de planejamento e controle da produção, segundo os quais, os planejamentos de curto, médio e longo prazo são claramente definidos. A partir disso, diversas ferramentas e práticas foram adotadas para que fosse implementada uma nova filosofia de construção. (MOURÃO; VALENTE, 2013)

Nesse processo, diversas atividades logísticas foram influenciadas e aperfeiçoadas por meio do uso de kanbans de estoque e argamassa, de fluxo de materiais, supermercados nos almoxarifados, entre outros.

\section{RESULTADOS DA PESQUISA}

A seguir, são apresentados a descrição de algumas práticas referentes à aplicação de ferramentas da filosofia lean na empresa estudada. Ressalva-se, aqui, que o texto a seguir encontra-se tal qual está escrito no material cedido pela empresa, seguidos de suas respectivas páginas para consultas posteriores.

\subsection{GERENCIADOR DE KANBANS DE ARGAMASSA}

O gerenciador de kanbans de argamassa é uma ferramenta que se encontra bastante consolidada na C. Rolim Engenharia. Trata-se de um painel que possibilita organizar a produção de argamassa por tempo e quantidade.

Os funcionários colocam em um cartão, as informações relacionadas à quantidade de traços, tipo de traço, local de entrega desejado e nome da equipe. Em seguida, o inserem em um quadro com demarcações de horários, para que as horas do dia anterior sejam necessárias para a utilização deste traço, a fim de que o betoneiro responsável já tenha em mãos pela manhã as primeiras solicitações e que não haja entrega dos traços. A solicitação de kanbans no quadro de gerenciamento possibilita ao betoneiro o nivelamento de sua produção diária, garantindo o abastecimento uniforme de todas as equipes da produção.

Ao longo do dia referente ao período, o betoneiro carrega as gericas e as identifica com argolas correspondentes ao tipo de argamassa e placas referentes ao pavimento onde será deixado o material, conforme informações fornecidas ao kanban. Dessa forma, o fluxo de informações independe da comunicação oral, pois o responsável pelo transporte vertical dessas giricas tem conhecimento de onde deixá-las sem mesmo trocar uma palavra com o betoneiro que as preencheu com os traços. Esta comunicação é clara e evita quaisquer mal entendidos.

A partir desta ferramenta, foi gerada uma nova organização no fluxo de informações e gerenciamento dos pedidos de argamassa, provocando a diminuição de desperdícios antes cometidos pela falta de identificação e da má comunicação. Logo, a diminuição no tempo de produção de pedidos foi notada e menos material foi consumido. Quanto menor a margem de erro, menos desperdícios (MOURÃO; VALENTE, 2013, p. 17-19).

\subsection{KANBANS DE ESTOQUE MÍNIMO}

O Kanban de estoque mínimo é uma sinalização de cor. Este deve ser devidamente calculado para os principais insumos da obra, aqueles de uso frequente, como tijolos, cimento, areia grossa, areia fina e brita, de modo a garantir um abastecimento de até dois dias de consumo na obra, no caso interno da empresa, a fim de que os responsáveis pela aquisição desses materiais tenham tempo suficiente para entrar em contato com o fornecedor e receber novo estoque, impedindo as quebras de atividades da obra.

Seu funcionamento é simples: se o estoque atual da obra é superior ao estoque mínimo calculado, o kanban utilizado para o insumo é de cor verde, significando abastecimento satis- 
fatório. Se o estoque atual da obra é inferior ao estoque mínimo calculado, o colaborador que se utiliza deste material sinalizará a seu colaborador fornecedor de material que o estoque está baixo e necessita de reabastecimento por meio de um kanban de coloração vermelha (MOURÃO; VALENTE, 2013, p. 23-24).

\subsection{KANBAN DE MATERIAIS}

O kanban de materiais é uma ferramenta lean implementada recentemente pela empresa. Sua ideia partiu de uma evolução do kanban de Argamassa, a fim de abranger outros materiais de grande importância na obra e que possuem fluxo vertical constante para os pavimentos em produção, como, porcelanato, cerâmicas e divisórias de gesso.

Similarmente ao papel de gerenciamento de kanbans na central de argamassa, há um painel de gerenciamento dos kanbans de material, em que eles são depositados na tarde do dia anterior ou pela manhã, pelas equipes de produção, e o responsável pelo fluxo de materiais na obra gerencia este painel e cuida do devido abastecimento dos pavimentos (MOURÃO; VALENTE, 2013, p. 24).

\subsection{ORGANIZAÇÃO E TRANSPARÊN- CIA DE ESTOQUE}

O controle visual de estoques facilita muito as atividades na obra, pois garante que o conhecimento das quantidades e localização dos materiais não fique centralizado no papel do almoxarife, ou seja, descentraliza-se o conhecimento e a atividade não fica completamente dependente de um funcionário.

A fim de estabelecer um padrão de organização para os almoxarifados da C. Rolim Engenharia, foram adotadas as seguintes práticas:

a) organização do matricial dos materiais, como uma "batalha naval" sobre as prateleiras, com cada material recebendo uma letra e um número correspondente a uma linha e coluna na prateleira. $\mathrm{O}$ almoxarifado possui um Manual de Localização de materiais que informa o código (letra+número) de cada material, de posse do almoxarife e de seus auxiliares;

b) leitor óptico nos almoxarifados para facilitar a entrada e saída (no sistema de controle) dos 20 insumos de maior fluxo dentro da obra;

c) quadro de Ferramentas e Funcionários que torna bastante transparente que equipamentos estão sendo utilizados diariamente por quais funcionários e em que quantidade;

d) identificação dos estoques de materiais ao longo da obra (que não podem ser armazenados dentro dos almoxarifados) (MOURÃO; VALENTE, 2013, p. 25).

\subsection{JUST-IN-TIME NO CANTEIRO DE OBRAS}

Normalmente, na hora de negociar certo produto com o fornecedor, atenta-se bastante para o seguinte tripé: preço, prazo e qualidade do produto. A forma de entrega do produto não é considerada relevante no momento de negociação. Dessa forma, o fornecedor entregará sua mercadoria no canteiro de obras como achar conveniente, o que, diversas vezes, não é o mais conveniente para a obra.

Isto se dá porque a obra possui um espaço limitado e insatisfatório para estoques e, quanto mais estoques de produtos, menos frente de trabalho e mais probabilidade de avarias deste material. Além disso, como preconiza a filosofia lean, é preciso reduzir os estoques nos canteiros, para que se possam perceber os diversos desperdícios inerentes às atividades.

O just-in-time é o principal pilar do Sistema Toyota de Produção e é um sistema de administração da produção que determina que nada deve ser produzido, transportado ou comprado antes da hora certa. De fato, o termo just-in-time significa, em inglês na hora certa.

Com este sistema, o produto ou a matéria prima chega ao local de utilização ou pro- 
dução somente no momento exato em que se fizer necessário, ou seja, os produtos somente são fabricados ou entregues a tempo de serem vendidos ou montados. O ideal é que não exista estoque parado. $\mathrm{O}$ próprio conceito do termo é relacionado à produção por demanda, onde primeiramente vende-se o produto para depois comprar a matéria prima e só depois fabricá-lo ou montá-lo.

Por motivo de todas as variabilidades inerentes à indústria da construção, é bastante difícil reduzir os estoques à hora de produção ou até segmentar uma grande compra em diversas pequenas compras (principalmente devido à flutuação dos preços). Entretanto, uma grande compra pode ser segmentada em diversas pequenas entregas, de modo a tentar reduzir os volumes de estoques no canteiro, mas mantendo a produção satisfatoriamente abastecida para quaisquer problemas de variabilidades.

A Gerência de Suprimentos e Logística liderou um processo de melhorias na entrega de tubulações de PVC na obra Lummi, como projeto piloto para a implantação do just-in-time. Os objetivos envolvem, a evolução posterior deste projeto para a implantação do Milk Run, inclusive. Os estudos se iniciaram com o mapeamento do fluxo de valor deste material para o estado atual, desde a realização de seu quantitativo, a devida solicitação junto ao fornecedor e a entrega na obra.

Em seguida, foi utilizada, uma solução para o estado futuro deste fluxo de atividades. A gerência de suprimentos e logística, aliada à gerência da obra, propôs a criação de um Master Plan para as instalações e a definição de lotes de serviço, de modo que fosse possível separar o pedido dos diversos tipos de tubulação de acordo com a necessidade de execução no canteiro. Além disso, foi definida a frequência das entregas, de modo que atendessem à de produção da obra. Estas frequências foram acordadas com o fornecedor no ato do contrato, de modo que ele pudesse entregar a mesma quantidade total de material com o mesmo preço de venda, mas em periódicas entregas programadas (e não tudo de uma vez).
Alguns benefícios já são visíveis, como a redução de estoques de tubulações em PVC no canteiro de obras, o que é bastante significativo, uma vez que esse material ocupa muito espaço. A liberação desta área de estoque representa mais uma frente de ataque para produção. Além disso, o controle e o cuidado deste material na obra também melhoraram, pois os grandes estoques mascaravam o desperdício de material e a falta de zelo.

Algumas considerações, porém, são importantes de ressaltar para que o processo possa fluir como planejado e propiciar melhorias ainda maiores; executar apartamento modelo conforme projeto para identificar incompatibilidades antes das aquisições das outras unidades privativas; focar nas liberações dos projetos de apartamentos de apartamentos customizados junto aos clientes, possibilitando uma visão de longo prazo mais realista e uma programação de demanda com variação menor; escolher os fornecedores certos (parceiros de materiais e serviços, incluindo também projetistas); e definir um líder na obra para o controle do projeto Just-in-time (MOURÃO; VALENTE, 2013, p. 36).

\section{CONCLUSÃO}

Neste trabalho, procurou-se por meio de um estudo de caso identificar qual a relação entre a logística e os processos relacionados a processos construtivos, considerando a evolução da importância dada aos sistemas logísticos ultimamente.

Pode-se compreender por meio da análise de práticas da construtora que há a integração entre sistemas de produção e a otimização de sistemas logísticos por meio de filosofias como o Just-in-time e a interpretação da filosofia lean expressa pelo uso de várias ferramentas como kanbans e transparência de estoques.

Portanto, pode-se perceber que o avanço de políticas de qualidade ligadas a várias ferramentas estratégicas que têm trazido resultados consideráveis para a empresa como a redução de custos e melhor gestão do canteiro de obras. Logo, considerando a importância e a atualidade 
do tema em questão, recomenda-se que, para estudos posteriores, seja feita uma maior explanação sobre o tema e uso de outras ferramentas de pesquisa, como uma entrevista com o gestor de cadeia de suprimentos e, se possível, ter acesso a dados quantitativos bem como ao levantamento de informações sobre logística reversa.

\section{LOGISTICS IN LEAN CONSTRUCTION: A CASE STUDY OF A CONSTRUCTION COMPANY IN THE CITY OF FORTALEZA, CEARÁ}

\begin{abstract}
Within the supply chain management approach, this article will address through a case study of a construction of Fortaleza, as philosophies such as Just in time can be related to logistics efficiency in various sectors. Through the description of practices related to the implementation of rationalization and inventory optimization tools construction processes it is evident as companies have obtained results of the migration from traditional thinking for a new look on productive activities, including logistics.
\end{abstract}

Keywords: Construction. Logistics. Just-in-time.

1 Este artigo foi premiado em $1^{\circ}$ lugar na categoria de Gestão e Operação logística no XXVI ENAGRAD Encontro Nacional dos Cursos de Graduação em Administração, no ano de 2015, em Foz do Iguaçu Paraná. Autores: Andriele Pinto de Amorim e Larisse Oliveira Costa.

\section{REFERÊNCIAS}

ARNOLD, J. R. Tony. Administração de materiais: uma introdução. São Paulo: Atlas, 1999.

BARBOSA, Adriano Aurélio Ribeiro; MUNIZ, Jorge; SANTOS, Angelo Urias dos. Contribuição da logística na indústria da construção civil brasileira. Revista de Ciências Exatas, São Paulo, v.2, n.1, 2008. Disponível em: <http:// periodicos.unitau.br/>. Acesso em: 01 maio 2015.

COLLIS, Jill; HUSSEY, Roger. Pesquisa em administração. 2. ed. Porto Alegre: Bookman, 2005 .

COOPER, Donald R.; SCHINDLER, Pamela S. Método de pesquisa em administração. 10. ed. Porto Alegre: Bookman, 2011.

DIAS, Marco Aurélio Pereira. Administração de materiais: uma abordagem logística. 5. ed. São Paulo: Atlas, 2010.

MATIAS-PEREIRA, José. Manual de metodologia da pesquisa científica. 3 . ed. São Paulo: Atlas, 2012.

MOREIRA, Daniel Augusto. Administração da produção e operações. São Paulo: Saraiva, 2012.

MOURÃO, Carlos Alexandre Martiniano do Amaral; VALENTE, Caroline Porto. Coletânea Lean \& Green. Fortaleza: C. Rolim Engenharia, 2013.

POZO, Hamilton. Administração de recursos materiais e patrimoniais: uma abordagem logística. 6. ed. São Paulo: Atlas, 2010.

RODRIGUES, Rui Martinho. Pesquisa acadêmica: como facilitar o processo de preparação de suas etapas. São Paulo: Atlas, 2007.

VERGARA, Sylvia Constant. Projetos e relatórios de pesquisa em administração. 14. ed. São Paulo: Atlas, 2013. 